\title{
Presentism and the Notion of Existence
}

\author{
Jerzy Gołosz ${ }^{1}$
}

Received: 9 November 2017 / Accepted: 4 March 2018 / Published online: 10 April 2018 (C) The Author(s) 2018

\begin{abstract}
The aim of this paper is to make presentism a dynamic view of reality by basing it on a notion of dynamic existence, that is, on a notion of existence which has a dynamic character. The paper shows that both of the notions of existence which are used in metaphysical theories of time (in presentism and eternalism) have a static character and, while such a notion is useful for eternalists, it is useless for presentists if they want to make their view able to remain in agreement with our everyday experience and self-consistent. It is demonstrated that both empirical and theoretical arguments indicate that the presentist should replace the notion of this static existence with the notion of a dynamic existence and that this maneuver allows the presentist to treat his/her existential thesis as equivalent to the thesis that time flows. Not only does this strategy allow us to express presentism in a simple, homogenous way which remains in agreement with our experience, but also permits us to solve some of the difficult problems which presentism faces, such as, for example, the objection of triviality and the question about the rate of time passage. Moreover, such an approach to presentism allows us to solve fundamental metaphysical problems concerning time such as the problem of the openness of the future and the fixity of the past, direction of causation, and relations between presentism and persistence through time by endurance.
\end{abstract}

Keywords Presentism $\cdot$ Eternalism $\cdot$ Dynamic existence $\cdot$ Flow of time . Becoming $\cdot$ Endurance

Jerzy Gołosz

jgolosz@iphils.uj.edu.pl; jerzy.golosz@uj.edu.pl

1 Department of Philosophy, Jagiellonian University, ul. Grodzka 52, 31-044 Kraków, Poland 


\section{Introduction}

We know-or seem to know-that the present is continuously changing from everyday experience; that instantaneous events which come into being have to cease to be because the past no longer exists. ${ }^{1}$ In a reverse way, future events-as we imagine them although they do not exist-come into existence for a moment to cease to be. These facts are taken at face value by presentism, that is the view usually formulated as the view saying that only the present things exist, or that only the present things are real; and denied by eternalism, the view saying that the past, present, and future things exist in the same way (or are ontologically on a par, or are equally real). ${ }^{2}$ But then-taking for granted that daily experience does not deceive us-some fundamental questions arise of where are past things, that is objects like Socrates, which existed in the past but no longer exist? What is their ontological status and what is the difference between them and fictitious objects, like, for example, Zeus and Dionysius? In a similar way, we can ask where are the future things and events which are to become present? Are they waiting somewhere for the right moment to come into existence or, maybe, moving from the future to the present and then into the past? Is the flow of time responsible for these phenomena? But if it is, what does the flow of time consist in, and can it avoid serious difficulties connected with the questions: How fast does time flow?; Why does the future seem to be open while the past is fixed? Why is the causation we observe in the world always future directed, that is, why do causes precede effects, in spite of the fact that the physical interactions (with the exception of weak interactions) are time reversal invariant? Why do we have traces of the past and no traces of the future? And, finally, why do at least some objects, for example, the author of this paper and their readers, persist through time-as our experience seems to indicate-retaining our strict (or literal, or numerical) identity, that is, why do we endure and not have temporal parts? ${ }^{3}$

These are fundamental metaphysical questions and this paper will try to answer some of them by analyzing the problems in two ways: from an empirical point of view and the metatheoretical point of view ${ }^{4}$ or-in other words - by tracing an

\footnotetext{
1 The paper develops ideas from Gołosz (2011, 2012, 2013, 2015, 2017c).

2 Because I am looking for a proper formulation of presentism, I will concentrate on the two main competing views of presentism and eternalism and will not consider the Growing Block Universe Theory, according to which the past and the present (but not the future) exist or are equally real (see e.g. Broad 1923; Tooley 1997).

3 There are two opposite views on persistence: endurantism and perdurantism. According to the latter, things perdure, meaning persistence through time by having temporal parts, persisting things are here treated as mereological aggregates of temporal parts, none of which are strictly identical with one another. Usually, the enduring of things generally assumed by presentists is defined as a persistence over time by being wholly present at each time but, as it was noticed by Merricks (1994: 182), “(...) the heart of the endurantist's ontology is expressed by claims like '[object] $O$ at $t$ is identical with [object] $O$ at $t^{*}$," For the author of this paper, this second condition alone suffices for the definition of endurantism and is a better criterion of endurance so it will be used in what follows.

4 Taking into account the theory-laden nature of observation, it is not so easy to differentiate between the empirical and theoretical (or metatheoretical) approach to problems; I assume (crudely) the empirical approach to be the one which is interested in our world while the theoretical (or metatheoretical) consists in the analysis of our theoretical knowledge.
} 
upward and downward path to the problems. This first means a requirement to look for a solution which remains in agreement with our everyday experience, while the second point of view means that the solution should provide us with satisfactoryor at least promising - answers to the questions raised above and that this solution should remain in agreement with empirical sciences.

The second section of the paper will try to show that our daily experience seems to force us to assume the existence of the flow of time; the third will try to prove that the properly understood passage of time compels us to reconceptualize presentism, and that to this end we should swap the common notion of existence, which has a static character, for a new one-dynamic. This third section and the next one will also attempt to demonstrate that the proposed formulation of the ontological thesis of presentism will turn out to be equivalent to a thesis expressing the existence of the flow of time and as such it can provide us with satisfactory, or at least promising answers for the above mentioned difficult questions. The fifth section examines the problem of the agreement of the proposed version of presentism with the empirical sciences. The paper ends with some conclusions.

\section{St. Augustine's Challenge}

As that clear-sighted observer of reality-especially concerning time-St. Augustine noted in the famous 11 th book of the Confessions:

Boldly for all this dare I affirm myself to know thus much; that if nothing were passing, there would be no past time: and if nothing were coming, there should be no time to come: and if nothing were, there should now be no present time. Those two times therefore, past and to come, in what sort are they, seeing the past is now no longer, and that to come is not yet ? As for the present, should it always be present and never pass into times past, verily it should not be time but eternity. If then time present, to be time, only comes into existence because it passeth into time past; how can we say that also to be, whose cause of being is, that it shall not be: that we cannot, forsooth, affirm that time is, but only because it is tending not to be? (St. Augustine 1912: 239)

There are controversies about St. Augustine's approach to time, largely centered around whether it is subjective or objective. Although I am a supporter of the latter, I will not assume this stance in this paper but rather what I claim is that every supporter of presentism should treat the phenomena described by the author of the Confessions as objective and that s/he should explain the issues raised by him.

What are the issues raised by St. Augustine? There is one condition and two important questions. Beginning with the first, he wrote that if nothing passed away, the time called the past was not; and if nothing were coming, the time to come was not either; and if nothing were, then the time called the present could not be either. This means exactly that if the flow of time did not exist, the present would not exist either, and in such a case we could not claim that the past was and the future will be. And because the presentists maintain that the past was, that the future will be, the 
present exists, and that there was a time when our present events were the future, they must admit the existence of the flow of time. What is also important here is that presentists cannot trade the monadic property of "being past", for the B-relation "earlier than", the monadic property of "being future" for the B-relation "later than", and the monadic property of "being present" for the B-relation "simultaneous with" because these relations_-as was noticed by McTaggart (1908)—are fixed and do not change in time so in such a case there would be no coming into existence and no passing away and the condition posited by St. Augustine would be not satisfied. So, because the adherents of presentism claim that the present exists but must pass away, that the past existed and the future will exist, they must accept the following condition, which deserves to be called St. Augustine's Condition (AC) ${ }^{5}$ :

AC Presentism has to admit the existence of the flow of time

St. Augustine also asks in the further part of the citation:

Q1 Those two times then, past and to come, how are they, seeing the past now is not, and that to come is not yet?

And the second question in the remaining fragment of the quotation, which can be briefly formulated as:

Q2 How can we say that the present is, if it only comes into existence for a moment and passes into time past, that is, if it is tending not to be?

Now, I would like to discuss the second problem, which has the form of the question Q1. This question is fundamental and not so easy to answer. We know, of course, that the future and the past do not exist (although they did exist or will exist, respectively) when we take this word in the tensed meaning, the problem is, however, that this does not exhaust all aspects of the subject. For, when we analyze the ontology of presentism in its standard version, we can say only about objects that $d o$ exist and that nothing more exist: the ordinary meaning of the word exist, as we use it in ontology and which I will later call static because it has a static character, only allows one to say that something does exist, or does not exist. Nonetheless, although Socrates and Dionysius do not exist (in the tensed meaning of this word), there is a fundamental difference between them: the first did exist and the second did not. So, how to express the ontological difference between them if both do not exist (in the tensed meaning of this word), or-saying this in a simpler way-where are past things, what kind of ontological domain do they form, "how are they"? The eternalist can simply say that Socrates does exist (in the tenseless meaning of this word), ${ }^{6}$

\footnotetext{
5 See Gołosz (2017c: 288).

6 After Quine (1960: 170), we can introduce tenseless verbs in the following way: "We can conveniently hold to the grammatical present as a form but treat it as temporally neutral." I am not interested in this paper in the question of the existence of abstract objects and consequently I will ignore this issue.
} 
and Dionysius does not, the presentist, however, should not use tenseless language, at least s/he must not use it as his main philosophical language. So, how should the presentist explain the difference between Socrates and Dionysius, that is, what is the ontological status of the past and what is the difference between the past and fiction? And a similar problem arises for the future: what is its ontological status? It is obvious that there must be some difference between what will happen (for example, in London tomorrow) and what will not (for example, paradise on Earth), although both do not exist.

The answer to this question can be sought by invoking the condition AC: the difference between Socrates and Dionysius is that there was a time when the first existed and there was no time in which the second did, and that it is the flow of time which is responsible for the fact that Socrates ceased to be, and for the ontological difference between him and Dionysius, who has never existed. This entails once again that the presentist should accept the flow of time as an essential part of his ontological position. Temporarily setting aside the problematic question of what the flow of time consists in, the rub lies in the fact, that the simple acceptance of the flow of time in a form of moving now still does not explain all aspects of the second issue; we still do not know what it means that some objects like Socrates did exist although they do not exist (in the tensed meaning of this word) and where are they, that is, what is the ontological status of the past. The point is that in the domain of our ontology we only include objects which exist, where the word "exist" is understood in the tensed meaning by the presentist, and tenseless by the eternalist. There is no place for objects which existed or will exist.

St. Augustine's condition also sheds some light on the second of St. Augustine's questions Q2; this is the flow of time which is responsible for the transient character of the present, that events that exist have to cease to be. But this third problem of St. Augustine shows us something more as well; if the present is continuously passing, we cannot simply say that the present things statically exist at some fixed moment of time. But that means that the usual notion of a fixed existence at a moment of time is not appropriate for expressing the transitory character of the present, and that it should be changed in such a way as to make it dynamic if we want to remain in agreement with our experience.

\section{Presentism, Flow of Time, and Dynamic Existence}

St. Augustine's observations (realistically interpreted) show us, as the above analysis tried to demonstrate, that the presentist should introduce the thesis about the existence of the flow of time into his ontological view and that s/he should formulate his/ her position in a dynamic way. Many presentists are often unaware of this problem ${ }^{7}$ and they usually formulate their position with the aid of the single ontological thesis

\footnotetext{
7 There are some exceptions. For example, Hestevold and Carter (2002: 493) claim that presentism should imply the passage of time in the form temporal becoming and Gołosz (2011, 2012, 2013, 2015, 2017c) maintains that the thesis about existence of the flow of time is a fundamental claim of presentism.
} 
that only present things exist, or that only present things are real. ${ }^{8}$ To escape the triviality problem, ${ }^{9}$ they sometimes formulate their view in a more sophisticated way after Lewis (1986) by using the notion of existence simpliciter, for example in the form: "Only present things exist simpliciter"; or "Necessary, if $x$ exist simpliciter, then $x$ presently exists." the triviality objection is a controversial issue. ${ }^{11} \mathrm{I}$ will not, however, examine this question because I am going to show that we can find a better solution to this problem in another way and which at the same time introduces dynamics into presentism.

If it is correct that presentism has to admit the existence of the flow of time, then the essential issue arises of whether the presentists' theses in a standard form really entails the existence of the flow of time. So the question is whether from the theses recalled in the first paragraph of this section alone (and with no other assumption) the existence of the flow of time can be inferred. ${ }^{12}$ It was shown, however, that it is generally impossible. ${ }^{13}$ To see this let us imagine a simple model of the possible world-let us call it $W^{\dagger}$ while calling our actual world $W$-exactly similar to our present world $W$ at some fixed moment $t_{0}$, but such that in $W^{\dagger}$ there existed nothing in the past of $t_{0}$, and there will exist nothing in the future of $t_{0}$. It would be a static "frozen" or "petrified" world with a momentary present at $t_{0}$ but without a flowing time, with no events and no things in the past of $t_{0}$, and similarly without events and things in the future of $t_{0}$. It would be a "frozen" (or "petrified") version of presentism, which, of course, is not in agreement with our experience but this is not under consideration. The point is that all the above mentioned ontological theses of presentism are true in the world $W^{\dagger}$ although there is no flow of time in the model which means that it is impossible to infer the passage of time from these theses.

Presentists can look for the solution to this problem by defining presentism as a simple conjunction of the two theses about existence of the present (only) and the flow of time. Certainly, it would be a better definition of presentism because St. Augustine's condition AC would then be trivially satisfied. Nevertheless, such a solution has some flaws: firstly, presentism defined with the aid of the two theses which make use of ontological notions of different character-static existence in the first case and the flow of time possessing undeniably dynamic character in the

\footnotetext{
8 The first option can be found in, for example, Merricks (1995: 523); the second one, for example, is to be seen in Hinchliff (1996: 122-123).

9 The triviality problem for the controversy between presentism and eternalism consists in this that when we examine their ontological theses, saying that only present things exist-in the first case-or that the past, the present, and future things exist in the same way-in the second-it turns out that both these ontological theses are trivially true or trivially false, depending on the way we understand the verb "exists": in the tensed or in the tenseless way. See, for example, Merricks (1995: 523); and discussions of the problem in Zimmerman (2004). It was also shown by Savitt (2006) that application of the predicate "being real" does not allow one to escape the triviality problem because of the ambiguity of the term "real".

10 See, for example, Sider (2006: 76); and Hestevold and Carter (2002: 499).

11 See, for example, the critical analysis of Savitt (2006) and Gołosz (2013).

12 For example, Hestevold and Carter (2002: 500-501) claim that the presentist thesis in the just mentioned form implies becoming.

13 Such an argument was proposed in Gołosz (2017c: 289).
} 
second-would lead to an inhomogeneous view. ${ }^{14}$ Secondly, there is a long tradition of presentism consisting in treating the present as a totality of what tensedly exists, which would mean that sentences of the type "Only the present things and events (tensedly) exist" are analytically true. ${ }^{15}$ And thirdly-as I will show-the thesis about the existence of the flow of time, if properly expressed, suffices to conceptualize presentism in a satisfactory way. The clue to the right expression of the flow of time is the notion of becoming so I shall try to show this starting from an analysis of this notion. ${ }^{16}$

The application of the notion of becoming to express the dynamic nature of reality has a long tradition - to recall, for example, Bergson (1944), Whitehead (1967, 1978), Eddington, ${ }^{17}$ Broad as those who applied it. ${ }^{18}$ I shall analyze the notion of becoming proposed by Broad (1938), which is relatively clearer and-what is also important-was introduced to avoid the essential difficulty associated with the conception of the passage of time, that is, the question about the rate of time's passage. Broad noticed that the passage of time cannot be referred to itself because then the ratio of the same two quantities expressing the rate of time's passage is meaningless. Neither can it be referred to a second time dimension because in such a case the problem of the flow of time returns, leading to regressus ad infinitum. Instead of this, Broad introduced his primitive notion of absolute becoming, which cannot be analyzed further:

To "become present" is, in fact, just to "become", in an absolute sense; i.e., to "come to pass" in the Biblical phraseology, or, most simply, to "happen". Sentences like "This water became hot" or "This noise became louder" record facts of qualitative change. Sentences like "This event became present" record facts of absolute becoming. (Broad 1938: 280-281)

I do not suppose that so simple and fundamental a notion as that of absolute becoming can be analyzed, and I am quite certain that it cannot be analyzed in terms of a non-temporal copula and some kind of temporal predicate. (Broad 1938: 281)

Broad offered us a dynamic image of the world with the real passage of time: events come to pass, that is, future events which earlier did not exist come into existence to cease to be. The static B-relations "later than", "earlier than", and "simultaneous with" cannot be used to describe Broad's becoming because his absolute becoming introduces real change into the world: events come to pass while-as was noticed by McTaggart (to recall again) — the above mentioned B-relations are fixed and do not change. In the static world described by the fixed relations, there would be no place for coming to pass. For the same reason, absolute becoming cannot be

\footnotetext{
${ }^{14}$ See Gołosz (2017c: 290).

15 See Gołosz (2013: 53-55; 2015: 819). Such an interpretation of the present reveals the real origin of the triviality problem.

${ }^{16}$ See also Gołosz $(2015,2017 \mathrm{c})$.

${ }^{17}$ See ch. V of his (1929), called "Becoming".

${ }^{18}$ See Broad (1938), Savitt (2014), and Gołosz (2017c).
} 
treated as a tenseless notion because some events became, some events are becoming, and some other will become, which means that absolute becoming is a paradigmatically tensed notion.

It is easy to misinterpret Broad's conception if one only concentrates on an explication of absolute becoming by means of the happening of events, ignoring at the same time Broad's coming to pass. The happening of events is an ambiguous notion; it can be interpreted actively — just as coming into existence to pass —or passivelyas simply being an event at $(x ; t)$, or taking place at $(x ; t)$. If somebody ignores Broad's explication of becoming as coming to pass and interprets becoming as the passive happening of events at some spacetime locations, 12 then, of course, he receives the passive tenseless becoming and the static block universe of the eternalist. For example, such a misleading interpretation was proposed by Dorato:

I plan to begin by proposing a new analysis of such a notion [becoming], to be regarded, on the wake of Gödel (1949b), simply as the successive occurrence (coming into being) of tenselessly conceived facts or events." 19

My suggestion is to explicate, or rather simply equate becoming with the notion of 'taking place' or 'occurring', which is also the natural way to understand change in Broad's absolute, non-qualitative sense referred to above:

Def: Becoming is real if and only if events successively and mind independently take place at their own proper time of occurrence. ${ }^{20}$

The author equates becoming with taking place or occurring, which leads to a passive interpretation of becoming. This static interpretation ignores Broad's coming to pass and results in the notion of becoming being stripped of any dynamic connotations, and as such deforms Broad's absolute becoming. Such a conception of the becoming of events cannot, of course, be used to express the real flow of time.

Because I am looking for a conception of becoming which is self-consistent and can be in agreement with everyday experience, I would like to transform this notion so as to conform it to this experience-on the one hand-and our knowledge about the world-on the other. I would still treat this notion as a primitive notion-exactly as Broad did-but I will suggest in this section and in subsequent ones a number of proposals which will make this transformed notion more precise by determining some of its properties. ${ }^{21}$ Some of these proposals will justify swapping the term "becoming" for a new one of "dynamic existence".

Broad ascribed absolute becoming to instantaneous events, however, it seems that the world consists not only of events but, first of all, of things; we can simply equate events with acts of acquiring, losing or changing properties by things, which means

\footnotetext{
${ }_{19}$ Dorato (2002: 256) He describes his position as "a relational, tenseless view of becoming" (p. 270).

${ }^{20}$ Dorato (2002: 269). A similar interpretation was proposed by Savitt (Savitt 2002: 159-160) and by Dieks (2006). Dieks' proposal will be analyzed further. Savitt's interpretation was criticized in Gołosz (2017c: 291).

${ }^{21}$ In a similar way-let us say - as the axioms in the set theory make the primitive notion of set more precise.
} 
also changes in their position, velocities and relative configurations. For example, plants and animals are considered to be primary objects of evolution in Darwin's theory. Even the theory of relativity - contrary to what is widely claimedshould be interpreted as a theory in which primary ontology consists of things and not events: we ascribe, for example, mass, momentum and energy to particles or conglomerates of them and not to events. How, for example, will it be possible to ascribe mass and momentum to events, which do not possess them? How events can move, rotate, and interact one with another? The task of building things from events so as such constructions could possess mass, momentum and energy seems to be very difficult, if it is possible at all. ${ }^{22}$ Thus - in what follows-I would treat things as primary objects and events and states of affairs as secondary.

One can claim also that things are just the objects which in some way become or come into existence. It was noticed by Sellars who wrote: "only things can become in the sense of come into being." (1962: 556) I agree only partly with him; for presentists, both things and instantaneous events become in the sense that their existence has a dynamic character. The difference between them is that the latter come to pass, the former do not cease to be but persist-which results from our experience-by enduring, that is by keeping their strict (literal or numerical) identity. Even if some objects do not exist at present, such as for example dinosaurs or stars which formed heavy metals that we are-inter alia-built of, there still exist particles which they were built of.

The necessity of acceptance of the endurance of things and the fact that things (such as, for example, elementary particles, their smaller and bigger conglomerates like atoms, things on the Earth, planets, stars and so on) form a fundamental part of the furniture of the world justify-I am convinced-the swapping of the term "become" for a new one which I will call "dynamic exist". This new notion is understood in a tensed sense and is for the presentist-exactly as "become"-irreducible to the tenseless one (some objects like Socrates dynamically existed while others, like the Earth, dynamically exist and others, like research posts on the Moon, will probably dynamically exist). ${ }^{23}$

To complete the conceptualization of presentism, we have to introduce the notion of the present. As I wrote at the end of the last section, there is a long tradition of presentism to treat the present as all those objects (things and events) which tensedly exist. ${ }^{24}$ If we follow this tradition, we obtain the present defined as something which

\footnotetext{
22 This paper is based on the assumption of scientific realism which says that we should take scientific theories at face value, that is, we should understand them as scientists, who use these theories, and one cannot propose an ontology of a given scientific theory imposing such an interpretation on it which clashes with the interpretation current among its users. If one wanted to construe physical quantities in a theory in a non-standard way, one should prove that theory interpreted in such a way is reasonable and can work effectively. See Gołosz (1999: 5, 9).

23 This analysis is to be acceptable for both relationists and substantivalists (regarding the controversy of substantivalism vs relationism over substantivalty of space and time); the substantivalist can simply ascribe dynamic existence to space (or its parts).

24 See, for example, Prior (1970: 247): "the presentness of an event is just the event. The presentness of my lecturing, for instance, is just my lecturing"; Christensen (1993: 168): "To be present is simply to be, to exist, and to be present at a given time is just to exist at that time-no less and no more"; and Craig (1997: 37): "Presentness is the act of temporal being." See also Gołosz (2017c: 292).
} 
is dynamically existing, that is as dynamically existing things and events, and while instantaneous events come into being to cease to be, dynamically existing things can persist by enduring as, for example, me and my computer. Similarly, the past, that is, the past things and events, are here understood as things and events that dynamically existed (past events no longer dynamically exist, past things have been able to endure in the whole or in parts until now as, for example, the Acropolis of Athens or particles from early stars from population I and II, and the future as things and events that will dynamically exist (future events do not dynamically exist yet while some of the future things dynamically exist now in the present form, with present properties in present states and often unknown future states).

So as a result of these two steps, we have obtained the flow of time defined as the dynamic existence of all objects which our world consists of with instantaneous events which come into existence to cease to be, and dynamically existing things which persist by enduring, and the present as something continuously changing. Such an understanding of the flow of time is not only in perfect agreement with our experience, but also avoids, exactly like Broad's becoming, the problem of the question of the rate of time's passage because it only makes use of the primitive notion of dynamic existence and does not involve time in any way. ${ }^{25}$ What is especially worth emphasizing is that such an understanding of the flow of time provides us also with the right ontology for presentism because it says that exactly what dynamically exists are these things and events which we call the present. What is more, the present understood in such a way is dynamically changing.

In this way we can obtain a definition of presentism which satisfies St. Augustine's condition AC. It can be expressed in the form which I will call Dynamic Reality, which-making use of the notion of dynamic existence-expresses at the same time the ontological thesis of presentism and the reality of the flow of time:

Dynamic Reality: All of the objects that our world consists of exist dynamically. ${ }^{26}$

The proposed term "Dynamic Reality" (DR) is more adequate than a term of the form "The flow (or passage) of time" because time is not involved in this claim. What is more - as I shall propose in the fourth and fifth sections-although time is not involved in DR, that is, the thesis saying about existence of the flow of time, it exists and can just be regarded as a secondary entity constituted by the dynamically existing objects.

But what about the presentists' theses concerning the past and the future: do we still need an additional ontological thesis excluding the existence of objects other than present? Fortunately, we do not need such additional theses because DR says that all of the objects that our world consists of exist dynamically, which means that it is unnecessary to talk about not existing (dynamically) objects. That is, we have received the intended effect with the single thesis DR and three definitions of the dynamically existing objects (called the present), objects which dynamically existed

${ }^{25}$ See Gołosz $(2015,2017 \mathrm{c})$.

${ }^{26}$ In Gołosz (2013: 55), a similar ontological thesis was applied. 
and do not dynamically exist (called the past), and objects which do not dynamically exist yet (called the future).

The important consequence of such a construction is that we have received a dynamic version of presentism introduced with the aid of one single thesis (and the three definitions), which means that this position can now be expressed in a simple, homogeneous way, satisfying-what is more-St. Augustine's condition AC. That is an important advantage over other formulations of presentism which either do not satisfy AC or do so in an inhomogeneous way when this position is formulated with the aid of a conjunction of the two theses making use of notions which have different character.

It is now the right time to return to the triviality objection. The notion of dynamic existence is a tensed notion. Is it, then, justified to say that DR is trivial? The answer is no because the notion of the present is not involved in this thesis, neither are the past nor the future involved. And, it is obvious that the definitions cannot be accused of being trivial. DR simply states that all of the objects which our world consists of exist dynamically (what is equivalent to the existence of the flow of time), which can be true or false (this last assessment according to the eternalist, of course) but this is not trivial. On the contrary, this is a very important and deep claim about reality which can be examined by its explanatory value. Our world-as we observe it -is one which is dynamically existing (or becoming with enduring things) and continuously changing. And this gives us good reason to believe-I maintain-that DR is true. This claim needs, of course, more justification than the sentence given above, so I will try show in the next parts of the paper that the proposed conception can really explain some phenomena which we observe in a consistent way and make it possible to answer-at least in a preliminary way-some difficult metaphysical questions mentioned in the first part of the paper.

We can now examine some of the important properties of the introduced notion of dynamic existence. First of all, I would like to emphasize its dynamic character, which can be contrasted with the standard notion of existence which is used in the definitions of both standard versions of presentism and eternalism. For, both these views use the notions of existence which have a static character; it is fixed existence in fixed moments of time. The difference between them is that standard presentism talks about (tensed) existence in one fixed moment of time while eternalism is concerned with (tenseless) existence at all moments of time which leads to the formation of a petrified four-dimensional block universe. In contrast, DR introduces the dynamic form of presentism describing our World in statu nascendi-as dynamically changing: events come into being to cease to be, things dynamically exist enduring and changing their properties. ${ }^{27}$ According to DR, dynamic existence is ascribed to all of the objects of the world.

\footnotetext{
27 It was shown by Merricks (1994: 177-178; 1995: 526); and Hinchliff (1996: 124-129) that change does not involve inconsistency into presentism — contrary to what was claimed by Lewis (1986: 202204) - because, according to presentism, no object (dynamically) exist in two (or more) moments of time simultaneously.
} 
The next important feature of dynamic existence which I would now like to discuss is directionality. This is a very interesting property of dynamic existence that it is not symmetrical under time reversal. Events come into being to cease to be, that is forming the fixed past consisting of things and events which dynamically existed. On the contrary, the future does not exist dynamically yet and seems not to be fixed (at least some future events seem not to be determined), it has just to come into (dynamic) being. Things come into being persisting through time by enduring, that is - so to say metaphorically - they are "moving" into the future keeping their strict identity. This means that dynamic existence is intrinsically time-asymmetrical and, as such, it is in perfect agreement with our experience. What is worth emphasizing, is that this asymmetry consists in this that past things and events have already dynamically existed and as such are not only fixed, but also possibly known to us by their traces (for example, in our memory) and impossible to change for sure, while future things and events did not have these possibilities yet; we can sometimes predict them but we cannot remember them. This is the main difference between the future and the past; it would remain even if the future were determined.

The notion of existence that is usually used by presentists has a static character and does not have the property of directionality. If the presentists want to "move" the present to receive the flow of time, then-even if they are able to solve or omit the problem of "How fast is the present moving"- they can do it in both directions because there is nothing in this notion which can block such a maneuver. Of course, the presentists want to "move" the present towards the future but they desire to do so not as a consequence of their ontological thesis but only to be consistent with our experience: it does not follow from their notion of existence.

The last property of dynamic existence which I would like to discuss in this section concerns the problem of the relations between presentism and persistence through time. I assumed above that the dynamic existence in the case of things means persistence by enduring. It was assumed partly as a generalization of Sellars' becoming and partly as a conception "inferred" from our experience of persistence: as it was said above-metaphorically speaking — things are "moving" or "drawing" into the future. Both seem to justify the conviction that we (and other things) persist while keeping our strict identity. Thus endurance is-in the case of dynamic existence-just a simple logical consequence of the way in which we and other things exist. This does not mean, however, as I will try to show in the next section, that future moments of time are in some way waiting to be fulfilled by things and events because it would mean eternalism.

Thus endurance of things is here a simple logical consequence of the dynamic existence of things, that is, it is a consequence of their way of existence proposed in this paper. We can now compare this solution with other versions of presentism. Usually it is assumed that presentism implies endurance, I would like, however, to show that there is a logical gap in such inferences. This logical gap was benefitted by Brogaard's (2000) in her simple model of presentism remaining in accordance with perdurantism (called by her four-dimensionalism).

The above mentioned argument aiming to show that presentism implies endurantism is very simple: an object cannot have another object as a part if that other object 
does not exist, so if an object persists at all, it must endure. ${ }^{28}$ There is the logical gap in this argument because from the idea that the past and the future do not exist one cannot infer that the persisting object keeps its strict identity. It is possible, after all, that an object persists without keeping its strict identity in such a way that it is four-dimensional and its temporal parts (or stages) — not strictly identical with themselves-are coming consecutively into being. Such a model of persistence, which joins together presentism and perdurance, was proposed by Brogaard in her model, things have four dimensions (that is, they perdure) in the sense that they have an unfolding temporal dimension in addition to the three spatial ones. ${ }^{29}$

The problem is that presentism defined in the standard way does not imply that endurance is necessary; the presentists have to look for another rationale for their favorite way of existence. They can, of course, assume an additional postulate about endurance but then their view ceases to be homogenous. The presentism proposed in this paper, which is based on the notion of dynamic existence, solves this problem in a simple way without additional assumptions, a considerable advantage and virtue.

\section{St. Augustine's Questions Revisited: A New Insight into the Nature of Time?}

We can now return to St. Augustine's questions:

Q1 Those two times then, past and to come, how are they, seeing the past now is not, and that to come is not yet?

Q2 How can we say that the present is, if it only comes into existence for a moment and passes into time past, that is, if it is tending not to be?

With the aid of the conception of Dynamic Reality the second question Q2 can be answered in a simple way: events which we call present ones dynamically exist, which means that they come momentarily into being to cease to be. Things dynamically exist by enduring, which means that they come into being by continuously changing, by losing some properties and gaining others (including properties of spatial locations, velocities and relative configurations). Their every-time states cease to be exactly like instantaneous events. This way we have received the world which is continuously changing as it really seems to be.

Dynamic Reality also allows us to answer the first question: past events do not dynamically exist because they ceased to be; they did exist dynamically. But quite a different answer should be given in the case of things; the past things dynamically exist-lock, stock and barrel, or in parts. Of course, they are always changed, nevertheless they dynamically exist. So, for example, the Parthenon in Athens still dynamically exists although it is changed and does not look like it did in the time

\footnotetext{
28 See, for example, Merricks (1995: 524-526) and Loux (2006: 235-236).

29 Brogaard (2000, Sect. 3). It is also possible to imagine that in spite of spatiotemporal and causal continuity, there are no persisting things, just as there is no persistence of things in space.
} 
of Socrates. But as regards Socrates, can we also say that he dynamically exists? Socrates does not dynamically exist but the particles which he was built of did not vanish, they still dynamically exist, just as atoms of heavier elements dynamically exist-for example, carbon, oxygen and iron-which came into existence in the nuclear fusion reactions inside the hearts of hot stars billions of years ago. From such atoms he was built-and we are made from such atoms ourselves. They are parts of us and of our present world.

And what about the future? It does not dynamically exist yet, it will only come into (dynamic) existence. Contrary to the past, which dynamically existed and as such is fixed and cannot be changed, the future looks as if it were open-our experience seems to suggest this openness and quantum mechanics confirms this conviction-and perhaps it depends on our actions. But even if it is determined and not open, it is not in existentce and will just come into (dynamic) existence.

I have tried to show that the proposed solution to the ontology of presentism and the flow of time can provide us with the right answer to St. Augustine's challenge and that it can also explain in a simple way the other fundamental question: why the past is fixed and the future seems to be open. And now to turn to the last explanation which I would like to propose, the most speculative but also probably the most intriguing. It concerns the most mysterious phenomena we know-time. What is the origin and nature of time? The answer, I suppose, lies just in the way of existence of all objects which our world consists of. When I introduced the notion of dynamic existence, I never appealed to time itself, that is, I did not claim that future objects and future moments of time are somewhere waiting to be fulfilled by dynamically existing objects. I could not have done this because it would mean introducing the four-dimensional block universe of the eternalists into the presentist picture of the world and the resulting breakdown of St. Augustine's condition AC. What I have done was to introduce the notion of dynamic existence as a primitive notion which has the intrinsic property of directionality. This property means that dynamic existence distinguishes one direction - toward the future. So what about time? Where do future moments come from if they are not waiting somewhere to be fulfilled? There remains only one answer which is possible: time is, according to this proposal, a consequence of the way we and other inhabitants of the world exist, that is, it is a derivative of the dynamic existence of objects: time, that is consecutive moments of time-each of each constitutes momentarily present-are created by dynamically existing objects, whatever they are. ${ }^{30}$ In consequence of this, time is a parameter which can be used to mark (or label, or measure) consecutive stages of dynamic existence of objects. ${ }^{31}$

\footnotetext{
30 See also Gołosz (2015: 816-817).

31 I will show in the next section that, thanks to the locality of the dynamic existence of objects, time constituted by dynamically existing things is their individual time, which can be equated with the so called proper time of the theory of relativity.
} 


\section{Dynamic Existence and Empirical Sciences}

The proposed formulation of presentism-as a thesis about dynamic existence of the world, that is, the directional (into the future) persistence of all objects through time joined with keeping their strict identity (in the case of things) and creation of time, the thesis which can be identified with the flow of time-is purely metaphysical. However, the process which is described by this theory is fully objective and of fundamental importance to us so it is hard to imagine that such a process cannot be observed by scientists. Therefore the question arises as to whether there are any traces of the dynamic existence of the world and the flow of time in the empirical science, or simply whether can we find any positive argument in empirical sciences in favor of the existence of the flow of time understood in the proposed way.

Because we connect the flowing of time with the continuously changing present, to answer this question, one should point out what is now (and its shape), how it is changing and whether we can really find such a process of changing present in empirical science. I would like to begin to analyze this problem with recalling a widespread opinion about an alleged lack of the presence of now in empirical sciences; not only Einstein but also, for example, Adolf Grünbaum were their supporters. Einstein is an author of the well-known passage from the letter of condolence to his friend Michele Besso's widow after Besso's death: "People like us, who believe in physics, know that the distinction between past, present and future is only a stubbornly persistent illusion". ${ }^{32}$ In turn, Grünbaum (1967: 7) wrote that "no cognizance is taken of nowness (in the sense associated with becoming) in any of the extant theories of physics." However, such a view was criticized by Quentin Smith, who argued that it is rooted in a misapprehension, namely on a mistaken belief that a subject matter which uniquely pertains to observational physics should be represented in theoretical physics. ${ }^{33}$ Physical laws are universal which means that they have to hold everywhere and always and that is why we should look for now rather in observational physics. And, in fact, Smith showed that in observational cosmology we can find physical events that possess the property of presentness: the present value of $T$ ( $T$ being the Hubble age), the present value of energy density and vacuum energy density, the present temperature of the cosmic microwave background radiation, and so on. The presentness of some events does not appear, for example, in the equations of the theory of relativity, but that no more shows that no event is present-as argued Smith (1994: 5) - than the fact that the location of the earth is not mentioned in its equations shows that the earth is not located anywhere.

There is also a well-known problem of the 'shape' of the present which arose with the advent of the theory of relativity, with specific difficulties connected with the special and general versions of this theory. According to the special theory of relativity (STR), we have no distinguished hypersurface of simultaneity, which could play a role of now, and in turn Gödel (1949a, b) showed that we should not

\footnotetext{
${ }^{32}$ See Norton (2010) and Gołosz (2017b) for their doubts about Einstein's position.

${ }^{33}$ Smith (1985: 112-115); (1993: 21-23); (1994: 5); (2005: 477-478). The same point is emphasized by Dieks (1988: 459-460).
} 
introduce global hypersurfaces of simultaneity as a proposal for now because there are some solutions of the field equations of the general theory of relativity (GTR) for example, his own solution with closed timelike loops is just such a case-where no global hypersurface of simultaneity exists. These are not difficulties that cannot be overcome: to remove the first obstacle, it is sufficient to choose the present in a relativistically invariant way; and to remove both, it is sufficient to choose the local present as the point-like here-now (e.g. Stein 1968, 1991; Čapek 1976; Shimony 1993; Dorato 2002; and Dieks 1988, 2006) because this last solution is also relativistically invariant. ${ }^{34}$

Does the proposed formulation of presentism based on the notion of dynamic existence satisfy this criterion of locality? Fortunately, dynamic existence can be ascribed to singular objects which means that it has an intrinsically local character: each object dynamically exist forming its own point-like present. To recall Prior and Craig: "the presentness of an event $i$ just the event" (Prior 1970: 247); "Presentness is the act of temporal being" (Craig 1997: 37). As a consequence, the proposed in this paper notions of dynamic existence and the present have the desired local character and as such can be reconciled with GTR. This is, in fact-exactly as in the case of the directionality - an advantage of this notion and of the approach which makes use of it.

What is interesting and worth emphasizing is that the notions of dynamic existence and the present which are proposed in this paper have an essential advantage over Dorato (2002) and Dieks' (2006) proposals of reconciliation of becoming with GTR because they introduce a notion of becoming which has been stripped of the whole dynamics. Because I recalled Dorato's becoming earlier, I will only mention Dieks' relational, tenseless view of becoming here:

Thus, our proposal is that 'coming into being' means the same thing as 'happening'. Since everything that happens is recorded in the block universe diagram, 'coming into being' is also fully represented. There is no need to augment the block universe in any way.

This proposal boils down to a deflationary analysis of becoming: becoming is nothing but the happening of events, in their temporal order. (Dieks 2006: 170-171)

So according to this proposal, 'coming into being at $(x, t)$ ' is what it means to be an event at $(x, t)$. (Dieks 2006: 172)

Therefore, for example, according to Dorato and Dieks' proposal, the trial of Socrates comes (in the tenseless sense of this word) into being or happens (in the tenseless sense of this word) in $399 \mathrm{BC}$, and the death of Socrates takes (in the tenseless sense of this word) place or happens (in the tenseless sense of this word)

\footnotetext{
34 For example, (Dieks 2006: 157) wrote: "I propose that if we want to make sense of becoming we should attempt to interpret it as something purely local. Second, I address the question of what this local becoming consists in. I maintain that processes of becoming are nothing but the successive happening of events, and that this happening of events consists entirely in the occurring of these events at their own spacetime locations. This leads to a consistent view of becoming, which is applicable even to rather pathological spacetimes.".
} 
after the trial. But if these are tenseless facts (so called $B$-facts), ${ }^{35}$ which can be stated in sentences whose truth-value does not change, and where there is no place for the distinguished and changing present, so where is there room for the becoming and flow of time?

Dieks asks: "Events come into being by occurring, by happening; what other coming into being could there be?" (Dieks 2006: 170) The answer is so simple that one may wonder why he did not give it: to really come into existence of the objects which did not exist earlier there has to be a distinguished present which is continually changing and which cannot be a relational, static $B$ - fact; a tensed language to express these $A$-facts has to be used as well. The notion of dynamic existence proposed in this paper and the notion of the present derived from it are expressed in tensed language, the present (as what dynamically exists) is continuously changing, and that is why they introduce a real dynamics to the world. Thanks to this, the view which is proposed here is a real full-blooded presentism and not a tertium quid between presentism and eternalism as is the case of the position of Dorato and Dieks.

What is also worth emphasizing, in the conceptions of Stein $(1968,1991)$, Capek (1976), Shimony (1993), Dorato (2002), and Dieks (1988, 2005), the point-like present was chosen in order to be relativistically invariant solutions to the problem indicated by Gödel, or as a solution choosing epistemologically close (directly accessible) set of sense data, but not because of some purely ontological reason: the notion of present were chosen independently of the notion of becoming and similarly the status of time was not explained. However, in the proposed conception based on the notion of the dynamic existence, the local character of the present was a consequence of local character of dynamic existence and time is closely connected with dynamic existence: I wrote at the end of the last section that time is created or constituted by dynamically existing objects and it is a parameter which can be used to mark (or label, or measure) consecutive stages of dynamic existence of singular things.

Thanks to the locality of the dynamic existence of objects and the locality of now, time constituted by dynamically existing objects is their individual time, which can be equated with the so called proper time of the theory of relativity. What is more, by the conception proposed in this paper, we can receive not only an explanation of the origin of time but also the absent origin of dynamics of the point-like here-now moving along or traversing world lines of things in the conceptions like these of Čapek Whitrow (1980), Dieks (1988), and Shimony. ${ }^{36}$ They all introduced the moving now conceptions of the present with the now-points moving along or traversing world lines of things, but they were unable to explain what was the source of the

\footnotetext{
35 Tenseless facts, called also $B$-facts, include necessary facts and contingent facts concerning which events are simultaneous, or how much earlier or later events are than each other. Contingent facts concerning which events are present, or past, or future are called $A$-facts. See e.g. Mellor (1998: 19).

36 For example, Shimony (1993: 284) noted: "Something fleeting does indeed traverse the world line, but that something is not subjective; it is the transient now, which as a matter of objective fact is momentarily present and thereafter is past. Without this minimal amount of objectivity there cannot even be an illusion of transiency".
} 
dynamics of their now-points. The proposed conception points to the dynamic existence of physical things such as, for example, elementary particles or their conglomerates, as an origin of this dynamics.

It is sometimes claimed that nothing in known physics corresponds to the passage of time. ${ }^{37}$ As far as it only means that there is no theory of the flow of time in physics, I agree. ${ }^{38}$ What is more, I would like even to show that there are good reasons to believe that a theory of the (objective) flow time is to be sought-just as it was proposed above — on a deeper level in metaphysics, and not in science. ${ }^{39}$ And, interestingly enough, there are-outside and inside of empirical science-some powerful arguments for the existence of the flow of time and I will introduce them below.

So first of all, why should we search for the theory of the flow of time in metaphysics, and not in physics? We should do so-I am convinced-because every plausible theory of the flow of time ought to explain two things: firstly, why this that exists (that is, the present things) is continuously changing; and secondly, why we persist through time, keeping strict or numerical identity, or, in other words, why we endure. This means that in such a theory notions and conceptions that are analyzed just by metaphysics and not by science are involved: notions of existence, persistence through time, and diachronic identity over time.

Of course, there is no proof that a theory of the flow of time is beyond the reach of science (and there cannot be) and it cannot be a priori excluded that-as in the case of doctrine of atomism which was a purely metaphysical doctrine for over two thousand years - scientists will be able to propose some theory of the objective flow of time in the future. The author of this paper is, however, skeptical of such a possibility simply because - if the presented approach is correct - a fundamental notion of existence is involved in the flow of time, which is the basis for our thinking and which cannot be further explained by science. Science can analyze what entities are posited by our theories, that is which objects exist according to these theories. It also can investigate whether such and such things exist, such as the Higgs boson or subatomic particles which dark matter can consist of, and what their properties are, but cannot analyze - it seems - what it means that they exist.

However, even if we agree that metaphysics can provide us with a theory of the flow of time, the problem mentioned in the beginning of this section remains, namely, if the process which is described by such a metaphysical theory is fully objective and of fundamental importance for us, it should be in some way endorsed as such by science. So, is the existence of the flow of time authenticated by empirical sciences or not? I claim that not only should the answer be positive but, what is more, its impact on empirical science is so big that without the existence the flow of time our best scientific theories would be incomprehensible. And the point is that, as it is well known, the main subject of interest of physicists (who are, for example, interested in the evolution of universe) but also chemists (in the case of, for

\footnotetext{
37 See, for example, Davies (2002: 40).

38 In the next part of this section, I would like to show that physics (and other empirical sciences as well) allows us to analyze and describe dynamic processes of physical systems.

39 I follow Bergson, Whitehead, and James here.
} 
example, chemical processes in the non-equilibrium systems), biologists (for example, in Darwin's theory of evolution or theories describing evolution of ecosystems), sociologists (for example, in the theories describing the dynamics of social groups), psychologists (for example, in developmental psychology) are dynamic systems of different kinds. Scientists are searching for theories describing the evolution in time of such systems, which makes possible the understanding of the mechanisms that underlie these processes and making predictions. And so, for example, we use Darwin's theory of evolution to explain the evolution and variety of life on Earth, the GTR to understand the evolution of the universe-its past and the possible futureand quantum mechanics (QM) to analyze the evolution of quantum systems. Of course, we are also sometimes interested in the spatial distribution of the parts of some systems, for example, in the geographical differences of our biosphere, but nonetheless we explain these geographical differences by means of the temporal evolution in different climatic conditions and our interest in the temporal evolution of dynamic systems is incomparably greater.

From the point of view of somebody who denies the flow of time, it is hard to explain why we are so interested in the variability of different systems in time rather than in space, and why we are so interested in explanations in terms of former causes rather than in teleological ones. And it is especially hard for them to explain our asymmetrical interest in the temporal properties of dynamic systems both in science and in everyday life, namely why we care much more about the future than about the past. If they try to explain this by invoking the evolutionary and selectional value of such asymmetric preferences, as Mehlberg (1980: 200-202) and Horwich (1987: 196-198) did for example, they are obliged to explain why our past-oriented care and desires cannot be fulfilled and are useless, although those that are futureoriented are useful. Such an explanation cannot simply appeal to empirical facts on pain of begging the question, because these empirical facts (the future-oriented evolution) are already temporally asymmetric and this is just the asymmetry of the fixed past - the open (as we believe) future which is involved in this explanation and should be explained.

The world with the flow of time is the world-as it often emphasized in this paper-in statu nascendi. This is the world which is dynamically changing and if the proposed approach to the flow of time is correct, scientists should look not for the present and its "motion", but rather for the dynamic existence of the world, that is, for the dynamic evolution or temporal becoming of these systems. And it turns out that we really have theories which describe dynamically the temporal evolution of biological and physical systems, namely Darwin's theory of evolution in biology, and in physics such theories as, for example, Newtonian mechanics, Maxwell's theory, the theory of relativity, or quantum mechanics. These physical theories determine the derivatives of some physical entities, like momentum (in Newtonian's theory), or the electric and magnetic fields (in the case of Maxwell's equations), or the so-called scale factor describing the evolution of the universe (in the Friedmann equations derived from the Einstein field equations), ${ }^{40}$ or the system's wave

40 See e.g. Kopczyński and Trautman (1992: 156-161). 
function (in the case of Schrödinger equation in QM) with respect to time, that is, they describe how these entities are evolving or changing in time. Thus, contrary to what was claimed, for example by Davies and was recalled in this section, the adherent of existence of the flow of time can simply interpret such dynamic theories just as theories describing dynamic existence or temporal becoming of the world or respective parts of it, without, however, introducing a theory of the flow of time.

In the last part of this section I would like to briefly analyze the problem of the directionality of causation in the context of physics and to show that the proposed approach involving the notion of the dynamic existence can help us to solve this problem. Namely, if we consider the problem of the directionality of causation in the context of physics, it is reasonable to assume that physical interactions are involved in all causal relations and responsible for them, and then two difficult problems arise which are connected one with another and hard to explain: the problems of the direction of causation and of the asymmetry of traces. They are conjugated because we can suppose that this is just the directionality of causation in the forward direction which is responsible for the lack of the traces of the future: a charged particle, for example, can only leave a white track in a bubble chamber after moving through it because this particle can cause ionization of a superheated liquid. ${ }^{41}$ This causation, however, is forward directed and that is why we cannot observe now in the bubble charged chamber particles which will move through it in the future although we can observe traces of particles which moved in the past through the chamber. And when we try to find out why this causation in which electromagnetic forces are involved is future directed, we meet a difficult problem because electromagnetic forces are time reversal invariant. The problem is, of course, more general. In fact, all physical interaction - with the exception of weak interaction — are time reversal invariant, so why is the causation we observe in the world always future directed, that is, why events from the past and from the present affect those which occur later, but we have no evidence of backward causation?

The main source of this difficulty is that all physical interactions with the exception of weak interactions are time reversal invariant, that is, whenever a sequence of states $S_{1}, S_{2}, \ldots S_{\mathrm{n}}$ is possible according to time reversible laws of physics, then the reverse sequence of time reversed states $T\left(S_{\mathrm{n}}\right), T\left(S_{\mathrm{n}-1}\right), \ldots T\left(S_{1}\right)$ is also possible according to these laws (where $T$ is a time-reversal operator). To be sure, the weak interactions are not time reversal invariant, but they are not involved in the causal relations we observe in normal situations, for example when we are speaking, writing, walking, watching TV etc. ${ }^{42}$

\footnotetext{
41 There was a trial undertaken by Reichenbach (1956: 150-151) and his followers (Smart 1967, 2005: 469; and Grünbaum 1973: 235-236, 281-289) to explain the asymmetry of traces by entropy considerations, namely, by introducing space ensemble of branch systems with different levels of orderliness which can interact one with another. However, it was shown by Earman (1974: 34 - 45), that an assumption speaking about the asymmetry of causation concerning interactions between the two systems was involved in this reasoning and it was responsible for the asymmetry of traces. See also Horwich (1987) and Gołosz (2017b).

42 Feynman (1967, ch. 5) noticed a long time ago, shortly after the discovery of the CP symmetry violation, that the distinction between the past and the future cannot depend on asymmetries of weak interactions. See also Sklar (1974), Gołosz (2017a, b).
} 
The metaphysical conception proposed in this paper solves this problem by appealing to the dynamic existence of things. For even if physical interactions (with the exception of the weak interactions) do not distinguish any time direction and even if we assume that the interactions are immediate, according to the proposed conception, what is responsible for a direction of causation is the dynamic existence of things, which is - as I tried to persuade in the previous section-future directed. Interacting bodies dynamically exist in the future direction and just in this direction transport effects of interactions with themselves as is, for example, the case in the growing of microscopic bubbles along the ionization track in the bubble chamber or a change of momentum of interacting particles. That is why we always observe a causation which is future directed although we have good reason to believe that physical interactions are always involved in causation and these are (modulo weak interactions) time reversal invariant.

\section{Conclusions}

The paper tried to show that presentists should admit the dynamic version of presentism assuming the existence of the flow of time in order to be in accordance with everyday experience and to make their view self-consistent. It also attempted to demonstrate that the ontological thesis of presentism formulated with the aid of the notion of dynamic existence suffices for the correct formulation of presentism and that such a formulation gives us important theoretical benefits. Namely, it allows us:

1. To develop a full-blooded tensed theory of the flow of time, which avoids vicious circles and regressus ad infinitum and, thanks to locality, can be claimed to remain in agreement with the General Theory of Relativity;

2. To express presentism in a simple, homogenous way;

3. To satisfy St. Augustine's condition concerning the flow of time, and to answer his ontological questions concerning the past, the present, and the future;

4. To explain a possible origin of the moving present of our experience;

5. To explain what is the origin of asymmetry of time, and especially why the past is fixed while the future seems to be open and why we have traces of the past and no traces of the future;

6. To explain what is the origin of the directionality of causation in spite of the fact that physical interactions (with the exception of the weak interactions) are time reversal invariant;

7. To propose a possible explanation of the origin of the fundamental time of the Theory of Relativity, that is the so called proper time.

The last points in this list mean-if the proposed metaphysical theory is correct - that the presented conception is able to explain the fundamental problems we face in metaphysics: the problem of the origin of the direction of time (points 4, 5, 6 ) and the even more important problem of the origin of time itself (point 7). The explanatory value of the proposed conception and difficulty of the problems it solves 
should testify to the superiority of this conception over the standard formulations of presentism.

The proposed change in the metaphysics of presentism is not extensive-it only involves the alteration of precisely one notion, the notion of existence, and then, in consequence, a new approach to time-nevertheless it is fundamental just because it concerns our two most elementary notions: the notions of existence and time. The author of this paper, who is working on the common ground of physics and philosophy, is aware that the proposed conception, by looking for the solution to central problems concerning the physical world in metaphysics rather than in physics, goes against the mainstream of physics and philosophy of science. Nonetheless, he does not see any other possible solution to the above mentioned exciting puzzles. They are fundamental ones and need to be solved if we want to understand ourselves and the world we live in.

Acknowledgements The research contained in this paper has been supported by the National Science Centre, Poland, Grant OPUS 11 No. 2016/21/B/HS1/00807. The author would like to thank Agnieszka Proszewska and Aeddan Shaw as well as the anonymous referees of this paper for their comments.

Open Access This article is distributed under the terms of the Creative Commons Attribution 4.0 International License (http://creativecommons.org/licenses/by/4.0/), which permits unrestricted use, distribution, and reproduction in any medium, provided you give appropriate credit to the original author(s) and the source, provide a link to the Creative Commons license, and indicate if changes were made.

\section{References}

Bergson H (1944) Creative evolution, trans. by Arthur Mitchell, Random House, New York

Broad CS (1923) Scientific thought. Routledge \& Kegan Paul, London

Broad CD (1938) Examination of McTaggart's philosophy. Cambridge University Press, Cambridge

Brogaard B (2000) Presentist four-dimensionalism. Monist 83:341-356

Čapek M (1976) Inclusion of becoming in the physical world. In: Čapek M (ed) The concepts of space and time, D. Reidel, Dordrecht

Christensen FM (1993) Space-like time. University of Toronto Press, Toronto

Craig WL (1997) Is presentness a property. Am Philos Q 34:27-40

Davies P (2002) That mysterious flow. Sci Am 9:40-47

Dieks D (1988) Special relativity and the flow of time. Philos Sci 55:456-460

Dieks D (2006) Becoming, relativity, and locality. In: Dieks D (ed) The ontology of spacetime, vol 1. Elsevier, Amsterdam

Dorato M (2002) On becoming, cosmic time, and rotating universes. In: Callender C (ed) Time, reality, and experience. Cambridge University Press, Cambridge

Earman J (1974) An attempt to add a little direction to 'the problem of the direction of time'. Philos Sci 41:15-47

Eddington AS (1929) The nature of physical world. Macmillan, New York, Cambridge University Press, Cambridge

Feynman R (1967) The character of physical law. The MIT Press, Cambridge

Gödel K (1949a) An example of a new type of cosmological solution of Einstein's field equations of gravitation. Rev Mod Phys 21:447-450

Gödel K (1949b) A remark about the relationship between relativity theory and idealistic philosophy. In: Shilpp PA (ed) Albert Einstein: philosopher-scientist. Open Court, La Salle

Gołosz J (1999) On field's argument for substantivalism. Int Stud Philos Sci 1:5-16

Gołosz J (2011) Upływ czasu i ontologia. Wydawnictwo Uniwersytetu Jagiellońskiego, Kraków

Gołosz J (2012) Na czym polega upływ czasu. Diametros 34:2-21 
Gołosz J (2013) Presentism, eternalism, and the triviality problem. Logic Log Philos 22:45-61

Gołosz J (2015) How to avoid the problem with the question about the rate of the time's passage. Rev Port de Filos 71:807-820. https://doi.org/10.17990/RPF/2015_71_4_0807

Gołosz J (2017a) Weak interactions: asymmetry of time or asymmetry in time? J Gen Philos Sci 48:19_ 33. https://doi.org/10.1007/s10838-016-9342-z

Gołosz J (2017b) The asymmetry of time: a philosopher's reflections. Acta Phys Pol B 48(10):1935-1946

Gołosz J (2017c) Presentism and the flow of time. Axiomathes 27:285-294. https://doi.org/10.1007/ s10516-016-9305-3

Grünbaum A (1967) Modern science and zeno's paradoxes. Wesleyan University Press, Middletown

Grünbaum A (1973) Philosophical problems of space and time. D. Reidel, Dordrecht

Hestevold HS, Carter WR (2002) On presentism, endurance, and change. Can J Philos 32:491-510

Hinchliff M (1996) The puzzle of change. Philos Perspect Metaphys 10:119-136

Horwich P (1987) The asymmetries in time: problems in the philosophy of science. The MIT Press, Cambridge

Kopczyński W, Trautman A (1992) Spacetime and gravitation. PWN-John Wiley, Warszawa-Chichester

Lewis D (1986) On the plurality of the worlds. Basil Blackwell, Oxford

Loux MJ (2006) Metaphysics: a contemporary introduction. Routledge, London

McTaggart JME (1908) The unreality of time. Mind 68:457-484

Mellor DH (1998) Real time II. Routledge, London

Merricks T (1994) Endurance and indiscernibility. J Philos 91:165-184

Merricks T (1995) On the incompatibility of enduring and perduring entities. Mind 104:523-531

Norton J (2010) Time really passes. Humana Mente: J Philos Stud 13:23-34

Prior A (1970) The notion of the present. Studium Generale 23: 245-248, Reprinted in Metaphysics: The Big Questions, Inwagen, P., Zimmerman, D.W. (eds.), Blackwell, Malden

Quine WVO (1960) Word and object. The MIT Press, Cambridge

Reichenbach H (1956) The direction of time. In: Reichenbach M (ed) University of California Press, Berkeley

Savitt S (2002) On absolute becoming and the myth of passage. In: Callender C (ed) Time, reality, and experience. Cambridge University Press, Cambridge

Savitt S (2006) Presentism and eternalism in perspective. In: Dieks D (ed) The ontology of spacetime, vol 1. Elsevier, Amsterdam

Savitt S (2014) Being and Becoming in Modern Physics. The Stanford Encyclopedia of Philosophy (Summer 2014 Edition), Edward N. Zalta (ed.), https://plato.stanford.edu/archives/sum2014/entries/ spacetime-bebecome/

Sellars W (1962) Time and the world order. In: Feigl H, Maxwell M (eds) Scientific explanation, space, and time. Minnesota Studies in the Philosophy of Science, University of Minnesota Press, Minneapolis

Shimony A (1993) The transient now. In: Search for a naturalistic world, vol. II. Cambridge University Press, Cambridge

Sider T (2006) Quantifiers and temporal ontology. Mind 115:75-97

Sklar L (1974) Space, time, and spacetime. University of California Press, Berkeley

Smart JJC (1967-2005) Time. In: Borchert DM (ed) Encyclopedia of philosophy. Thomson Gale, Detroit, New York

Smith Q (1985) The mind-independence of temporal becoming. Philos Stud 47:109-119

Smith Q (1993) Language and time. Oxford University Press, Oxford

Smith Q (1994) General introduction: the implications of the tensed and tenseless theories of time. In: Smith Q, Oaklander N (eds) New theory of time. Yale University Press, New Haven

Smith Q (2005) Time, being, and becoming. In: Borchert DM (ed) Encyclopedia of philosophy. Thomson Gale, Detroit

St. Augustine (1912) The confessions of St. Augustine, translated by William Watts, vol. I, II, William Heinemann, London

Stein H (1968) On Einstein-Minkowski space-time. J Philos 65:5-23

Stein H (1991) On relativity theory and openness of the future. Philos Sci 58:147-167

Tooley M (1997) Time, tense, and causation. Oxford University Press, Oxford

Whitehead AN (1967) Science and the modern World. The Free Press, New York

Whitehead AN (1978) Process and reality. The Free Press, New York

Whitrow GJ (1980) The natural philosophy of time. Thomas Nelson and Sons Ltd., London

Zimmerman DW (ed) (2004) Oxford studies in metaphysics, vol 1. Oxford University Press, Oxford 